\title{
AIM2015: VALIDATION AND INITIAL RESULTS FROM AN OPEN-SOURCE AVIATION SYSTEMS MODEL
}

\author{
Lynnette M. Dray ${ }^{* a}$, Philip Krammer ${ }^{\dagger a}$, Khan Doyme ${ }^{\ddagger a}$, Bojun Wang ${ }^{\S a}$, Kinan Al \\ Zayat**a $^{* *}$ Aidan O'Sullivan ${ }^{\dagger \mathrm{a}}$ and Andreas W. Schafer ${ }^{\text {ta }}$
}

aAir Transportation Systems Lab, UCL Energy Institute, 14 Upper Woburn Place, London, UK, WC1H 0NN

Declarations of interest: none.

\section{ACKNOWLEDGEMENTS}

This work is supported by EPSRC grant EP/M027031/1. We are grateful for their support and for the help and assistance of many other people without which this project would not have been possible; in particular Marius Macys and Weibo Li for their efforts in data-gathering, and Tony Evans for his assistance with updates to the input data and airport-level modelling. EPSRC had no direct involvement in the work carried out for this paper.

\footnotetext{
*Corresponding author. Tel: +44 (0)7886678564 Email: 1.dray@ucl.ac.uk.

$\dagger$ Email: Philip.krammer.13@ucl.ac.uk.

¥Email: k.doyme@ucl.ac.uk.

§ Email: bojun.wang.13@ucl.ac.uk.

***Email: k.zayat@ucl.ac.uk.

${ }^{\dagger}$ Email: aidan.osullivan@ucl.ac.uk.

\# Email: a.schafer@ucl.ac.uk.
} 


\title{
AIM2015: validation and initial results from an open-source aviation systems model
}

\begin{abstract}
Policies aimed at influencing air transportation must operate in a complex, interacting global system of passengers, airlines, airports and other stakeholders. Tools which are capable of assessing policy outcomes in this situation are vital. Given the high uncertainty about future demand, costs and technology characteristics on policy-relevant timescales, such tools also need to allow the evaluation of outcomes from a wide range of plausible futures. This paper presents the validation study and initial baseline results from a comprehensive, open source update of the global AIM aviation systems model. We show that running the model from 2005 to 2015 using 2005 base year data reproduces well the observed demand levels and patterns of growth. Running from a 2015 base year, we project global demand in 2050 of between 13,800 billion and 46,000 billion revenue passenger kilometres (RPK), respectively 2.2 and 7.4 times year 2015 values, depending primarily on the future scenario for population, income and oil price assumed. Absent any radical change in aircraft technology, this would lead to global direct $\mathrm{CO}_{2}$ emissions from aviation of between 876 and 2,500 Mt, or 1.5 to 4.4 times the year-2015 level. This wide level of baseline variation may present a challenge for long-term aviation policy and its adaptability to different futures.
\end{abstract}

Keywords: Aviation emissions, Aviation technology, Systems modelling, Policy assessment, Emissions mitigation

\section{INTRODUCTION}

The global aviation system faces both opportunities and challenges in the near and distant future. Passenger demand continues to grow rapidly, with world growth in RPK of nearly 5\% per year projected over the next twenty years (Airbus 2016, Boeing 2016). However, 
increasing demand within a system where major airports are capacity-constrained (e.g. Madas \& Zografos, 2008) can lead to increases in airport and airspace congestion, which in turn can lead to increasing delays and costs for airlines. It may be difficult to reconcile these increases in demand with local, regional and global ambitions for emissions reduction. Although there is significant potential for technology and operational changes to lower fuel use and emissions per RPK (e.g. Schäfer et al. 2016), it is unlikely to offset the strong growth rate. It is probable therefore that the impact of aviation externalities such as $\mathrm{CO}_{2}, \mathrm{NOx}$ and particulate emissions will continue to grow.

Airport capacity decisions are often made as part of wider regional or country level transportation policy. The decision process can be lengthy and controversial (e.g. Airports Commission, 2015). These decisions will interact at multiple levels with environmental policy. For example, ICAO's global CORSIA scheme aims to offset aviation emissions via the purchase of emissions allowances by airlines from other sectors (ICAO, 2016a). Global noise and local emissions regulations typically impact new aircraft designs and airlines' ability to keep older aircraft models in their fleets (e.g. ICAO, 2017). Environmental policy may also be applied at the world-regional level, such as the application of the EU emissions trading scheme to aviation; the country level, such as the UK's air passenger duty (e.g. Mayor $\&$ Tol, 2007); or at the level of individual airports, for example by the application of landing fees by aircraft emission category. These policies all have the potential to affect where airlines fly and which technologies and operational measures they use, which in turn interact with capacity decisions (which may also be contingent on meeting environmental goals).

Given that aviation is a global system with many interactions between different stakeholders, the costs and benefits of environmental policies, capacity expansion and other interventions need to be evaluated in this context. In response to the complexity and difficulty of such decisions, a global aviation systems model which can jointly assess both environmental and 
capacity policy is being developed under the Airport Capacity Consequences Leveraging Aviation Integrated Modelling (ACCLAIM) project, a collaboration between UCL, Southampton University and Imperial College London. This model will build on the existing AIM model (e.g. Reynolds et al. 2007; Dray et al. 2014), introducing airline competition and network change (e.g. Evans \& Schäfer, 2011) amongst other new features. As a first step to this project, we have significantly updated the AIM model with new demand, itinerary choice, fare, aircraft performance, airline cost, aircraft size choice and technology choice models, and made it available as an open source model. This paper describes this updated AIM model, assesses its performance using year 2015 and year 2005 base year data, and uses the model to project demand and emissions to 2050 for a series of baseline scenarios to assess system sensitivity to key inputs.

Although various other aviation systems models and transport models with aviation elements exist (e.g., AERO, 2002; Waitz et al., 2006; Rich et al. 2009), the updated version of AIM is novel in a number of respects, most notably its open source status. Also notable is its focus on the airport level, which allows the projection of detailed aircraft movements, delay and local emissions impacts alongside effects on the global climate. The updates to the demand model significantly improve the representation of airline and passenger response to policy, allowing cost pass-through to be studied more directly and passenger routing responses to changes in cost, frequency and journey time to be assessed.

The rest of the paper discusses the new components of the model. Section 2 describes the existing model and how the new components fit into it; Section $2.1-2.8$ then describe each new component in turn. Section 3 shows model output for 2005 and 2015 base year data and a range of scenarios for future variables. We draw conclusions and discuss the future development of the model in Section 4. 


\section{UPDATED MODEL ELEMENTS}

The AIM model has a modular structure. Broadly, a demand module projects the true originultimate destination passenger demand between cities, and which airports and routes these passengers will choose; an airport and airline activity module projects the resulting airportlevel schedules, delay and demand for aircraft; an aircraft movement module projects the inflight routing of these aircraft; and an aircraft performance and cost module projects the fleet composition, fuel use, costs and technology uptake (e.g. Reynolds et al. 2007; Dray et al. 2014). These modules iterate until a stable solution is found. The converged aircraft movements and emissions data can then be used in global climate, noise, air quality and economic impact modules. A simplified diagram of the structure of the first four modules is shown in Figure 1. Sub-models which have been added or substantially updated for this version as compared to the model used in Dray et al. (2014) are shown in white.

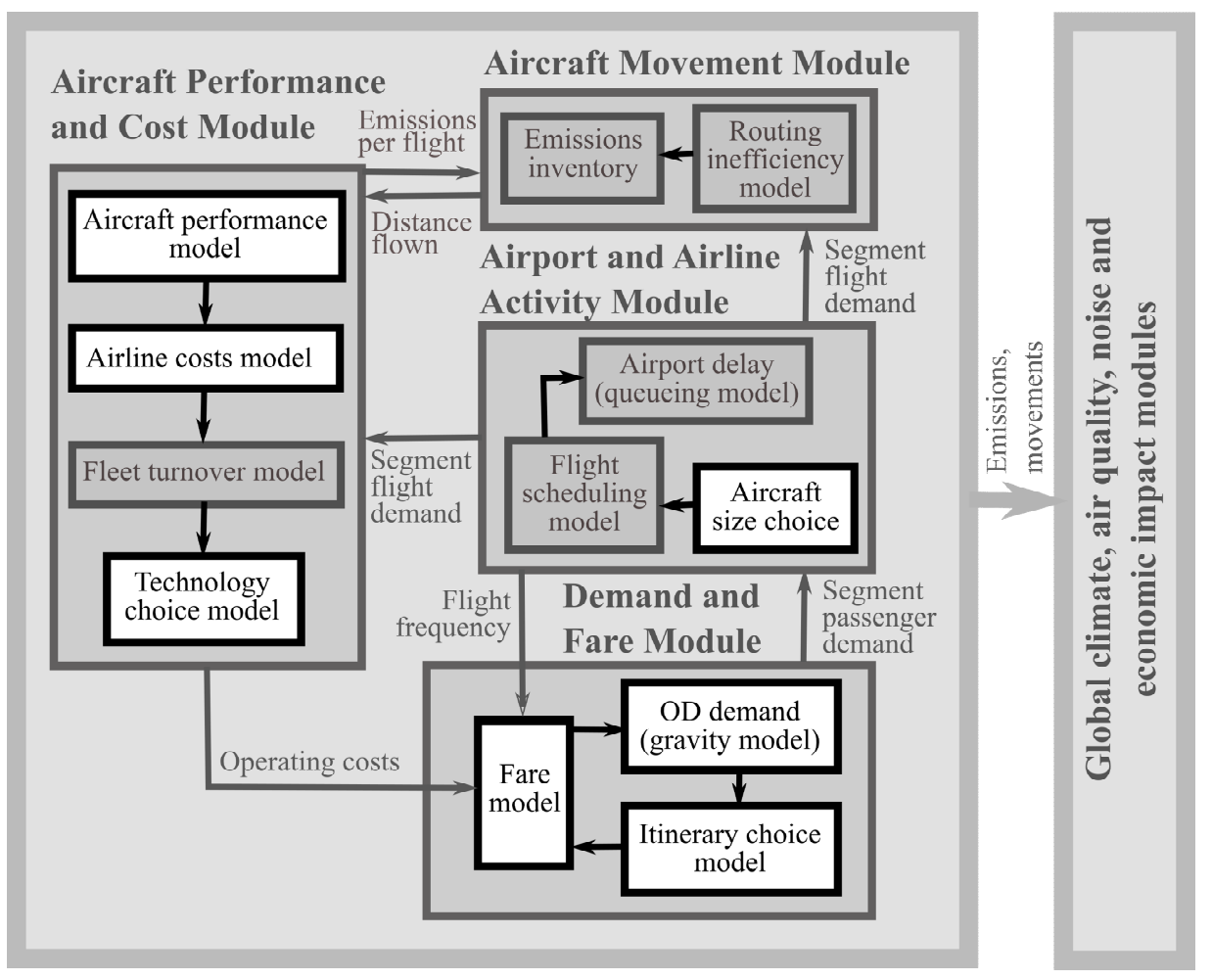

Figure 1. The updated AIM model structure. 
Sub-models shown in grey remain largely unchanged from the previous version of AIM.

These models have already been published on extensively and testing and validation can be found in the papers on the respective models, e.g. Evans (2008; scheduling and delay model); Reynolds (2009; aircraft movement module) and Dray (2013; fleet turnover model).

As this paper is focussed on the updated components of the aviation systems models, we do not discuss the climate, air quality, noise and economic impact models here. More information can be found in Krammer et al. (2013; climate model), Barrett and Britter (2009; air quality model) and Torija et al. (2017; noise model). Further details of the integration of these models and the data used in developing them can be found in the AIM model documentation (Dray, 2018).

\subsection{OD demand model}

The OD demand model projects true origin - ultimate destination demand between a set of global cities. For the updated model, we use a gravity-type model similar to that used in the original AIM (e.g. Dray et al. 2014):

$\ln N_{o d}=\beta_{0}+\beta_{1} \ln \left(P_{o} P_{d}\right)+\beta_{2} \ln \left(I_{o} I_{d}\right)+\beta_{3} \ln \left(f_{o d}+v o t t_{o d}\right)+\sum_{i} \beta_{i} D_{o d}^{i}$

where $N_{o d}$ is the total passenger demand by any route between cities $o$ and $d, P_{o}$ and $P_{d}$ are the populations of the greater metropolitan areas of $o$ and $d$ respectively, $I_{o}$ and $I_{d}$ are the per capita household incomes of $o$ and $d, f_{o d}$ is the average fare for passengers travelling between these cities over all routes, vot is the passenger value of time, $t_{o d}$ is the average time (including delay) to travel between the two cities, $D_{o d}$ are dummy variables capturing other elements of the city-city connection (e.g. whether it is a domestic route, whether a road or high-speed rail link exists between the cities, etc.), and the parameters $\beta$ are estimated. Elasticity parameters by world region-pair and distance (short-, medium- or long-haul) are taken from Dray et al. (2014), including the use of IATA-recommended income elasticities 
(IATA, 2007). We additionally scale all origin-destination flows by the ratio of actual to modelled demand in the base year. This is an interim model for the current version of AIM; further improvements are in active development and are expected to be applied in the next update.

One additional source of uncertainty is that income elasticities may also vary over time as markets become more mature. As discussed in Graham (2006), income elasticities exceeding 1 can indicate an immature market. Some studies therefore reduce income elasticities for long-term projections to account for increasing market maturity. For example, DfT (2017) reduce income elasticities for passengers originating in the UK from 1.2-1.4 in 2016 to 0.8 1.0 in 2050 . There is also some evidence that passengers may become slightly less sensitive to changes in fare as markets mature; for example, Brons et al. (2002) project price elasticity reductions by 0.01 per year. However, the income elasticities in IATA (2007) for the US, which is arguably the world's most mature aviation market, are close to those for developing economies, with greater variation in income elasticity by distance than by market maturity. Additionally, a meta-analysis of aviation income elasticities by Gallet \& Doucouliagos (2014) finds a modest increase in estimated income elasticities over time, although this may be affected by the distribution of regions for which income elasticities have been estimated in different studies. In light of this, we use same the IATA elasticities for the whole of the projection time period, but also estimate what impact reducing income elasticities would have on total demand.

\subsection{Fare model}

Many factors affect the fares charged by airlines on a given route. For demand between cities $o$ and $d$, passengers will have the option of multiple different airport-airport itineraries $k$, from some airport $m$ in $o$ to some airport $n$ in $d$, and potentially via some number of hub 
airports. To account for this, we have estimated a detailed fare model to calculate the average fare for each available passenger itinerary:

$$
\begin{gathered}
\ln f_{\text {odk }}=\alpha_{0}+\alpha_{1} \ln F C_{o d k}+\alpha_{2} \ln C P_{o d k}+\alpha_{3} \ln C F_{o d k}+\alpha_{4} \ln C U I 16_{m n}+\alpha_{5} \ln A H H I_{m n} \\
+\alpha_{6} \ln L H H I_{o d k}+\alpha_{7} \ln F r e q_{o d k}+\alpha_{8} \ln N_{o d k}+\alpha_{9} \ln R S_{o d k}+\alpha_{10} \text { Nlegs }_{o d k} \\
+\alpha_{11} H_{o d k}+\alpha_{12}\left(C_{m}\right)+\alpha_{13}\left(C_{n}\right)
\end{gathered}
$$

where $f_{o d k}$ is the fare between cities $o$ and $d$ on itinerary $k, F C_{o d k}$ is the sum of fuel cost per passenger over all segments on the itinerary, $C P_{o d k}$ and $C F_{o d k}$ are the sum of per-passenger and per-flight based nonfuel costs over all segments on the itinerary, $C U I 16_{m n}$ is the mean of the average 16-hour capacity utilisation index (CUI) for airports $m$ and $n, A H H I_{m n}$ is the mean airport-level Herfindahl-Hirschmann Index $(\mathrm{HHI})^{\S \S}$ over airports $m$ and $n, L H H I_{\text {odk }}$ is the geometric mean of the city-pair HHI for all segments on itinerary $k$, Freq $_{\text {odk }}$ is the yearly frequency of the given itinerary, $N_{o d k}$ is the number of passengers using this itinerary, $R S_{o d k}$ is the share of the total origin-destination passengers on this city-pair using the itinerary, Nlegs $s_{\text {odk }}$ is the number of flight legs in the itinerary, and $H_{o d k}$ is the number of major hub airports used on itinerary $k$. The parameters $\alpha$ are estimated; $\alpha_{12}$ and $\alpha_{13}$ are origin and destination country fixed effects terms. Data on fares by itinerary, schedules and passenger numbers is taken from the Sabre Market Intelligence database for 2015 (Sabre, 2016). This database includes details about all scheduled passenger movements, including type and cost of ticket, and the exact itinerary flown in each case. Airline costs are generated by the airline cost model described in Section 2.7. Using the model, we obtain global fare per passenger$\mathrm{km}$ of 0.09 year 2015 US dollars in 2015 and 0.10 year 2015 US dollars in 2016, using the 2015 base year model. These numbers match well to global estimates of total airline revenue

\footnotetext{
$\S \S$ The HHI is the sum of the squares of the market shares (in passengers) of all airlines in the given market, and is used to assess the amount of competition in that market.
} 
per passenger-km performed (e.g. ICAO, 2016b) of around 0.11 year 2015 US dollars in $2015^{* * *}$.

More information on this model, the estimated parameters, and its validation is given in Wang et al (2017). Fares calculated by the fare model are combined with passenger shares for different itineraries given by the itinerary choice model (Section 2.3) to calculate average fares by origin-destination city pair, which are then used in the demand model (Section 2.1).

\subsection{Itinerary choice model}

Most air journeys give passengers multiple itinerary options. For example, travel may be direct or via a hub airport. Passengers may modify their decisions if the characteristics of one or more routing options change. We model passenger itinerary choice using a multinomial logit model. The number of passengers between cities $o$ and $d$ on itinerary $k$ is modelled as $N_{o d k}=\frac{N_{o d} e^{V_{o d k}}}{\sum_{j} e^{V_{o d j}}}$

where the deterministic part of the utility, $V_{o d k}$, for an itinerary $k$ between cities $o$ and $d$ is:

$V_{o d k}=\gamma_{0}+\gamma_{1} f_{o d k}+\gamma_{2} t_{o d k}+\gamma_{3} \ln$ freq $_{o d k}+\gamma_{4}$ Nlegs $_{o d k}+\gamma_{m}+\gamma_{n}$, and $f_{o d k}$ is the itinerary fare as estimated by the fare model (Section 2.2), $t_{\text {odk }}$ is the total itinerary travel time, freq $q_{\text {odk }}$ is the itinerary frequency, Nlegs $s_{\text {odk }}$ is the number of flight legs in the itinerary, the parameters $\gamma$ are estimated, and $\gamma_{m}$ and $\gamma_{n}$ are itinerary origin and destination airport fixed effects terms. Passenger numbers, schedule and fare data are taken

\footnotetext{
*** Note that we do not expect the two numbers to match exactly, as airline ancillary and cargo revenue are not included in our model. Ancillary revenue, which includes items such as food sales and website advertising, was around 3-8\% of total revenue for US network carriers in 2011 (Hao 2014), and cargo revenue is around 2\% (Stalnaker et al. 2016). Fare per RPK also includes some taxes that do not accrue to airlines. Nevertheless, we expect the two figures to be similar.
} 
from Sabre (2016), as for the fare model. More information on this model, including parameter estimates, is given in the AIM model documentation (Dray et al., 2017).

In combination, the gravity, itinerary choice, and fare models project the number of passengers on each airport-airport segment. The three models interact extensively with each other, with the fare model balancing the demand side with the supply components of AIM, here expressed via airline costs. To find a solution, we iterate between all components of the model until segment demand is stable on all modelled segments. The resulting base year demand by airport in the 2015 base year model for the top 50 global airports, as designated by 3-letter IATA identification code, is shown in Figure 2.

Global, 2015 base year

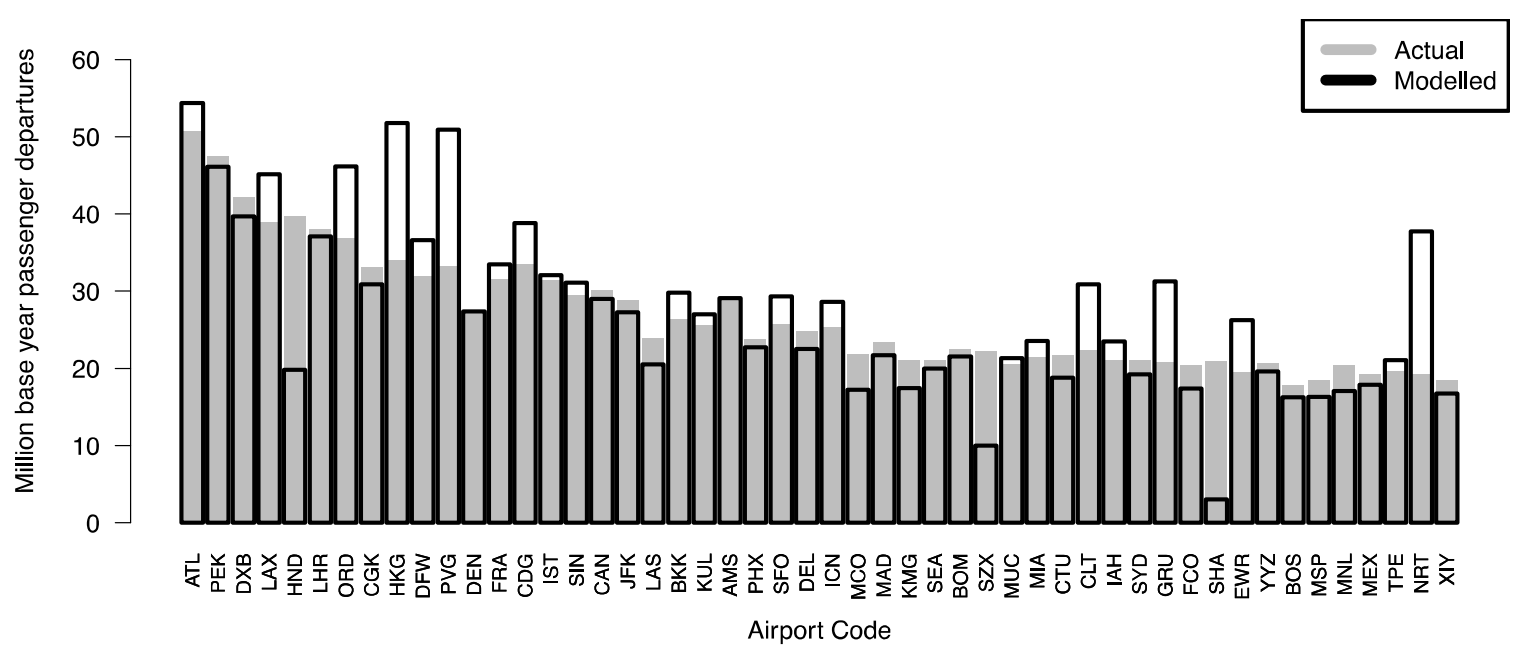

Figure 2. Total passenger departures by airport, top 50 global airports in the 2015 base year.

Modelled demand is typically within $10 \%$ of actual for most airports, with some notable exceptions in Asian multi-airport systems (e.g. SHA and PVG in Shanghai, and HND and NRT in Tokyo) where the distribution of demand between different hub airports is not fully captured at present. This will be addressed in future versions of the model. 


\subsection{Aircraft size choice}

Once passenger demand per segment is generated, this needs to be translated into a feasible flight schedule. The original version of AIM used a multinomial logit model to estimate which aircraft will be used on each segment (e.g. Reynolds et al. 2007). Combined with typical load factors for each segment this allows the overall and size-specific flight frequency to be estimated. For the updated version of AIM we have expanded the number of aircraft size classes modelled from three to nine (Table 1), based on the Sustainable Aviation ${ }^{\dagger \dagger}$ aircraft categories (Sustainable Aviation, 2015). The proportion of aircraft, $p r_{m n s}$, of each size class $s$ on each segment between airports $m$ and $n$ is estimated as:

$$
\begin{aligned}
& p r_{m n s}=\frac{e^{U_{m n s}}}{\sum_{j} e^{U_{m n j}}}, \text { where } \\
& U_{m n s}=\theta_{0}+\theta_{1} d_{m n}+\theta_{2} h_{m}+\theta_{3} h_{n}+\theta_{4} N_{m n}+\theta_{5} L F_{m n}+\theta_{6} R_{m}+\theta_{7} R_{n}+ \\
& \theta_{8} N L C C_{m n}+\theta_{9} H H I_{m n},
\end{aligned}
$$

and $d_{n m}$ is the distance between airports $m$ and $n, h_{m}$ and $h_{n}$ are dummy variables indicating whether $m$ and $n$ are major hub airports, $N_{m n}$ and $L F_{m n}$ are the number of passengers and the passenger load factor on the segment, $R_{m}$ and $R_{n}$ are the lengths of the longest runways at $m$ and $n, N L C C_{m n}$ is the number of low-cost carriers operating on the segment, and $H H I_{m n}$ is the segment HHI in terms of airline passenger share. More information on this model, including parameter estimates, is given in the AIM model documentation (Dray, 2018).

In Figure 3, we show the resulting proportion of aircraft of each size class by distance as projected by the model, compared to actual year 2015 flight schedule data (Sabre, 2016). Background colour bands show the modelled distribution of size class over distance and the

\footnotetext{
${ }^{+1 \dagger}$ Sustainable Aviation is a collaborative project between major UK airlines, airports, air navigation service providers and manufacturers, aimed at delivering a long-term strategy which allows the industry to grow in a sustainable fashion.
} 
overlaid black lines show the actual boundaries between size classes using schedule data. For most size classes, the distance distribution of use is reproduced well and the model and schedule data boundaries are close. However, use of the smallest size class of aircraft is under-predicted across all applicable distances, leading to an overlap of the schedule data area for the smallest size class (beneath the lowest black line) with the model data area for the second-smallest size class (the grey band marked '2').

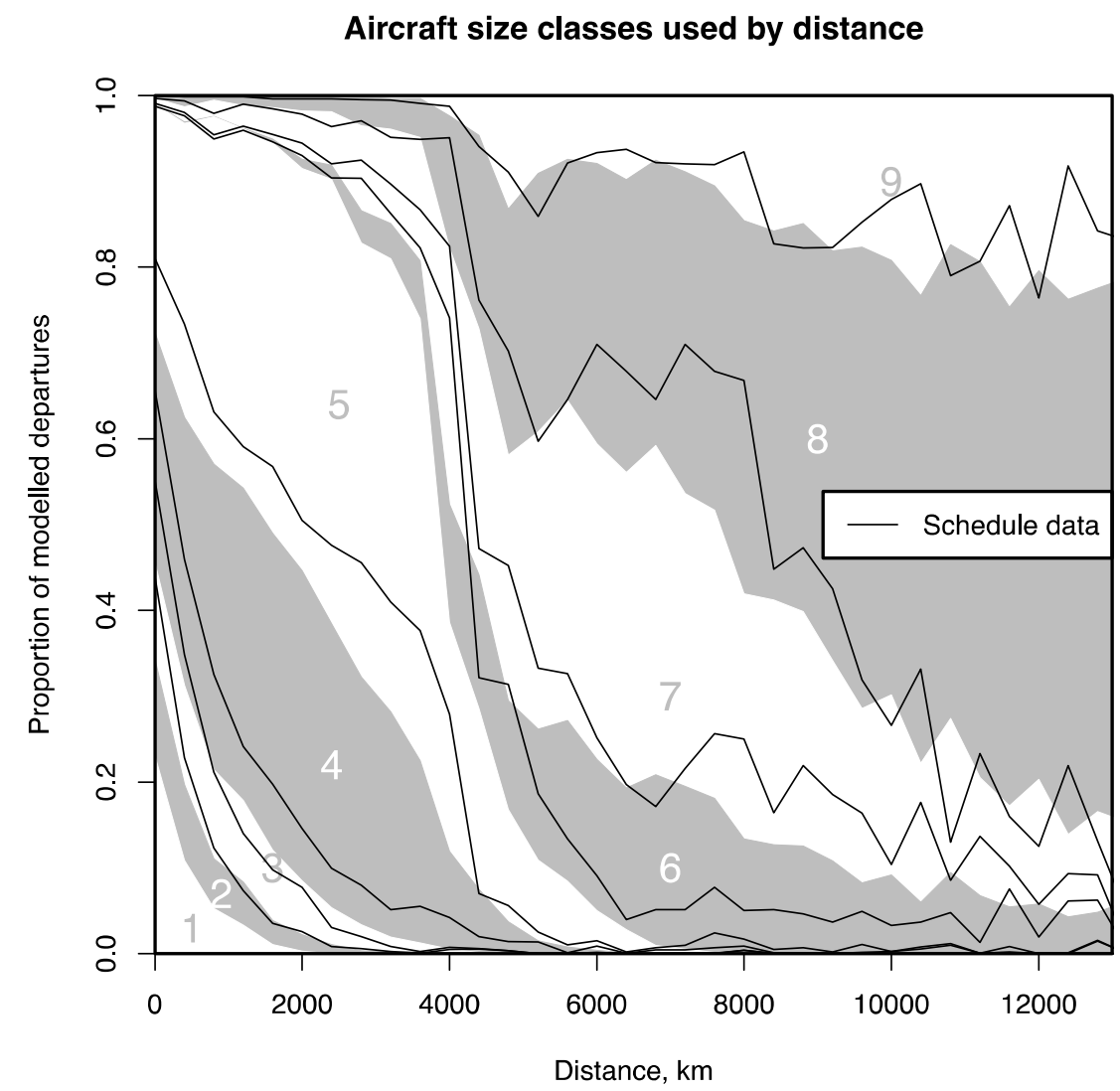

Figure 3. Modelled proportion of aircraft used by distance in the base year, compared to year 2015 schedule data.

Applying the model to the base year flight network, the total global fleet for size classes 2-9 is reproduced to within ten percent in each case, but for the smallest size class we underpredict demand for aircraft by around 30\%. This may reflect the specific use patterns of these aircraft and the carriers that use them, e.g. constraints at small regional airports with few 
facilities and small carriers with limited capital, which are not currently reflected in the model.

We assume historical load factor values by airport-airport segment are maintained unless there is a specific intervention to change them (e.g. a new technology or operational measure is introduced which has an effect on load factor). Historical load factors are obtained by combining passenger movement data with schedule on seats offered (Sabre, 2017). In combination with the typical number of seats per size category and the estimated proportions of aircraft types per segment, this allows flight frequency by aircraft size on a segment to be estimated. It also allows demand for flights by airport to be assessed, so that delays can be calculated using the delay model. Currently, we assume that the distribution of these flights throughout the day tracks base year values, and that airport capacity will be expanded as required to accommodate new demand; more sophisticated models in these areas will be developed in the next update to the model.

The demand for aircraft by size class and world region is compared to the currently-existing fleet to assess the number of new aircraft required. In the case that more aircraft are already in the fleet than are currently needed, we assume that the excess aircraft are put into storage; aircraft in storage may be reactivated in a subsequent year if demand increases enough that they are needed, or may retire directly from storage, depending on their age and the retirement model parameters (e.g. Dray, 2013).

Table 1. Aircraft size classes used in the updated AIM model Size Category Approx. seat range Reference aircraft
1. Small regional jet
$30-69$
CRJ 700
2. Large regional jet
70-109
Embraer 190
3. Small narrowbody
110-129
Airbus A319 
4. Medium narrowbody

5. Large narrowbody

6. Small twin aisle

7. Medium twin aisle

8. Large twin aisle

9. Very large aircraft
130-159

160-199

200-249

259-299

300-399

$400+$
Airbus A320

Boeing 737-800

Boeing 787-800

Airbus A330-300

Boeing 777-300ER

Airbus A380-800

\subsection{Aircraft performance model}

The original AIM model calculated fuel use by a simple fuel burn rate-based-approach. For the updated version, as well as expanding the number of aircraft size classes, we have also integrated a rapid fuel use and emissions model which calculates performance by flight phase based on interpolation from the output of the PIANO-X aircraft performance model (Lissys, 2017). Grids of fuel use and NOx emissions for the nine reference aircraft were calculated for climb, cruise and descent, for passenger load factors between 0 and 1 and stage lengths up to the aircraft's maximum range. We assume $95 \mathrm{~kg}$ for a passenger with luggage and an average of 4,500 kg hold freight (ICAO, 2009; ICAO, 2014). In operation, the model interpolates within these grids to find by-phase totals. For the gate, taxi and holding phases we use fuel use and emissions rates also derived from PIANO-X; for take-off and landing standard fuel use and emissions totals by type are used. The resulting fuel and NOx totals by flight phase are also adjusted by the stock and technology choice models (Section 2.8) to take account of the age profile of the fleet and changes in the use of different technologies over time. Figure 4 shows the block fuel output of the rapid performance model for the nine reference aircraft; more information can be found in Al Zayat et al. (2017). 


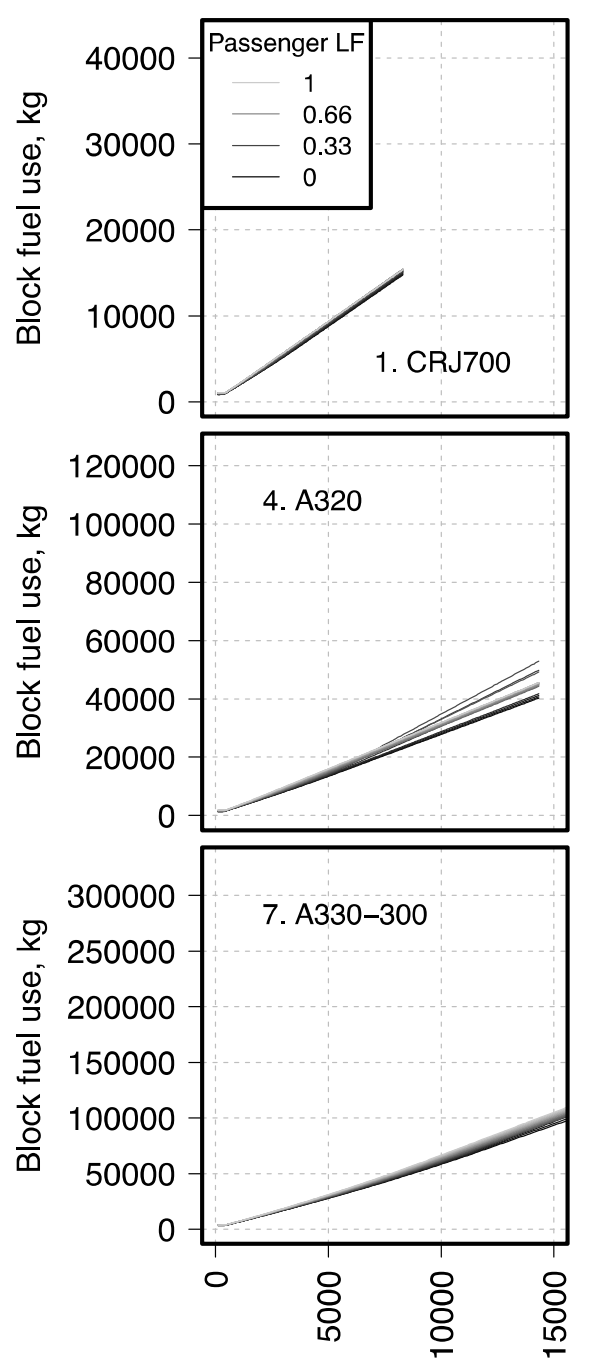

Distance, $\mathrm{km}$
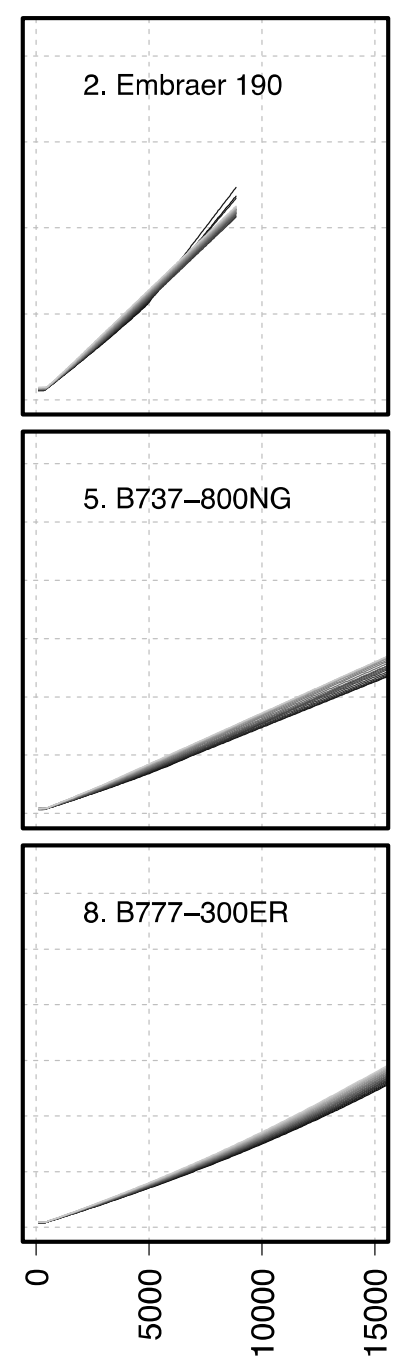

Distance, $\mathrm{km}$
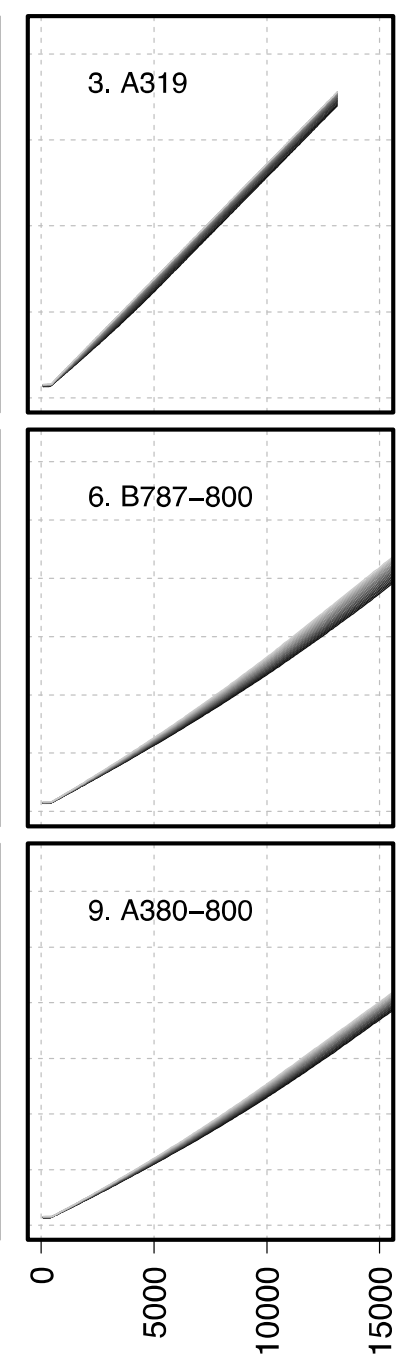

Distance, $\mathrm{km}$

Figure 4. AIM performance model block fuel use for the nine reference aircraft, by passenger load factor (LF) and stage length.

\subsection{Airline direct operating costs model}

A new model for airline direct operating costs is also estimated, based on the same nine aircraft size categories (Al Zayat et al. 2017). Costs are calculated on a per-passenger, peryear, per-segment or per-aircraft basis as appropriate and are divided into ownership (e.g. interest, depreciation and insurance), volume-related (indirect cost), landing, en-route, maintenance, crew, fuel and carbon costs. Landing and en-route costs by size category are derived from the RDC airport charges database (RDC, 2017). Other costs are derived from a range of sources, including BTS (2017), Flightglobal (2016) and Aircraft Commerce (2017). 
Fuel and emissions totals are derived from the aircraft performance model described in Section 2.6. Crew costs, volume-related costs and the labour component of maintenance costs are assumed to vary by world region-pair. Regional scaling factors are derived from ICAO (2009).

For the simulations shown here, we assume wage costs of the flight crew and of staff performing maintenance to remain constant in real terms when projecting into the future. This is based on an analysis of historical US airline cost data (BTS, 2017). However, it is unclear if this relationship will apply in future or for other world regions. An alternative assumption would be that staff costs grow in line with GDP. Modelled crew costs are around $30-50 \%$ of fuel costs, and assuming they increase in line with GDP per capita instead would add airline costs in 2050 roughly equivalent to increasing fuel prices by $40 \%$ in the central (SSP2) scenario modelled in Section 3.2. However, a much wider range of variation in fuel cost is modelled across scenarios in Section 3.2 and leads to only a modest variation in fare per RPK; therefore, the overall impact of this assumption across scenarios without extreme GDP per capita growth is likely to be small.

To illustrate the model outcomes, Figure 5 shows airline per-passenger direct and indirect operating costs by size class for four example flight segments in the base year, assuming a typical load factor per segment. Segment costs are used as input to the fare model described in Section 2.2. 

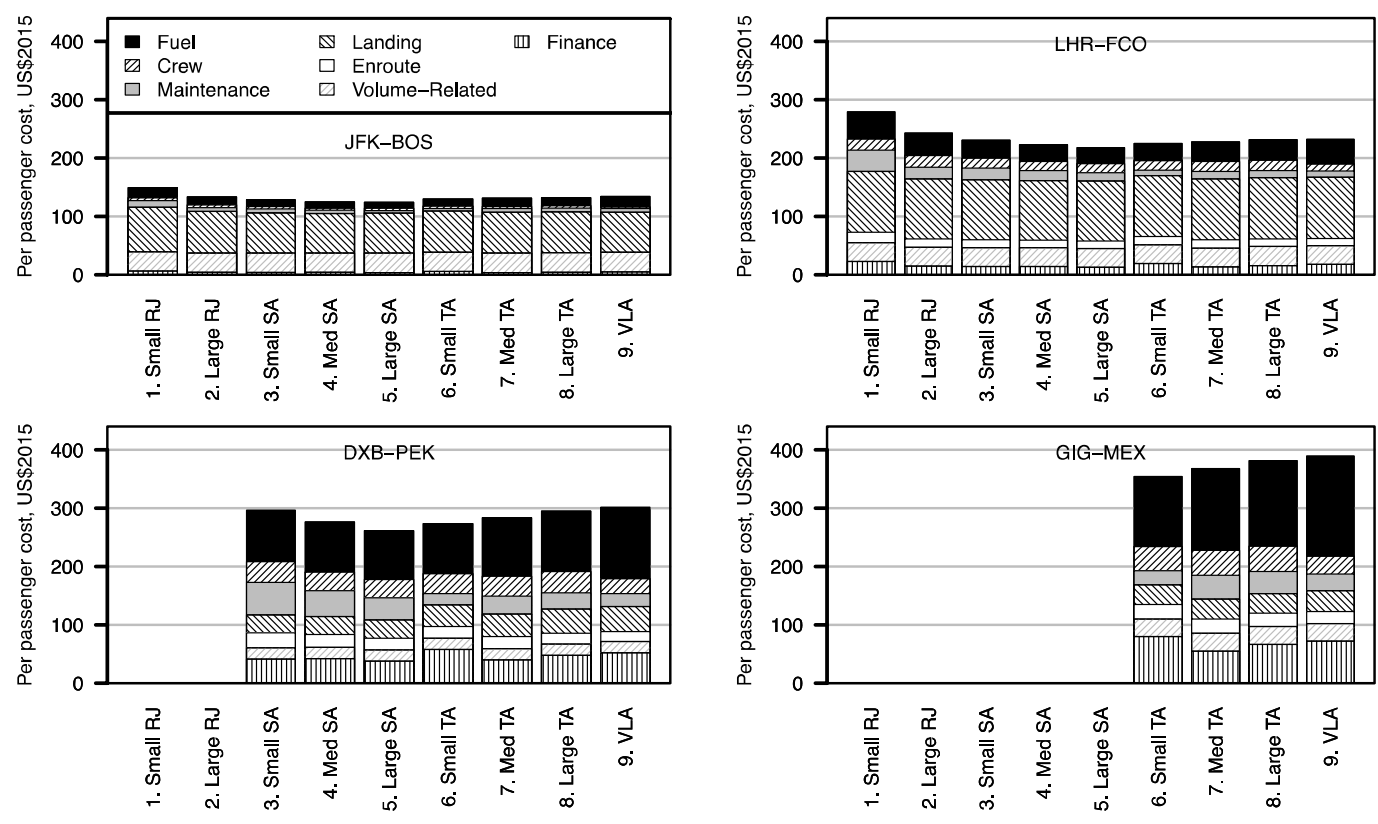

Figure 5. Direct and indirect operating cost model output for four example flight segments. Values are only shown where the stage length is below the maximum range of the reference aircraft ${ }^{\text {献. }}$

\subsection{Technology choice model}

The outputs of the airline cost and performance models are adjusted to take account of new technologies which may become available over the course of the simulation. This model was in place in the previous version of AIM (e.g. Dray et al. 2014), but has been updated with more technologies and the option to use a lens approach to assess the impact of uncertainty in technology parameters (e.g. Allaire et al. 2014). Technology parameters, including changes in aircraft operating costs by cost type and changes in fuel burn, are derived from Schäfer et al. (2016). Major technology options, such as next-generation aircraft models, are assessed using net present value over a seven-year period with a ten percent discount rate. Operational

JFK: John F. Kennedy Airport (New York), BOS: Logan Airport (Boston), LHR: London Heathrow Airport, FCO: Fiumicino Airport (Rome), DXB: Dubai International Airport, PEK: Beijing Capital International Airport, GIG: Rio de Janeiro International Airport, MEX: Mexico City International Airport. 
measures and retrofits are assessed using a three-year payback period. More details on the updates to this model can be found in Dray et al. (2018).

\section{VALIDATION AND BASELINE PROJECTIONS}

Model validation can take several forms. It may include validation of the model input data; validation of the assumptions and/or functional forms within the model; and testing the model output data against real-world outcomes. As the sub-models, their input data and assumptions have already been extensively tested (see individual references above for each model), we concentrate on the third form of validation. To validate the integrated model, we use two approaches. First, we take a hindcasting approach to test its predictive power: using a 2005 base year dataset, we project demand from 2005 to 2015 and compare to actual 2015 values. Second, we use a 2015 base year and look at how this model matches to 2015 data, how it projects demand and emissions into the future, and how sensitive it is to key input variables. These approaches are separate to the validation processes for individual model components, which are discussed in the references for each component cited above.

\subsection{5 base year projections to 2015}

We use 2005 base year data from the previous version of AIM (e.g. Dray et al. 2014), recalculated where necessary to accommodate the new models and increased range of aircraft size classes. For projecting into the future, the model requires estimates of population and income growth and oil and carbon prices. For the 2005-2015 period we source these values from Summers et al. (2016) and IEA (2016), on a country-level basis. Modelled passenger enplanements and revenue passenger-kilometres (RPK) are shown in Figure 6, compared to observations from World Bank (2016). Panels (a) and (b) show total, short-haul, medium- 
haul and long-haul enplanements and RPK by year. Panel (c) additionally breaks down RPK by world region.
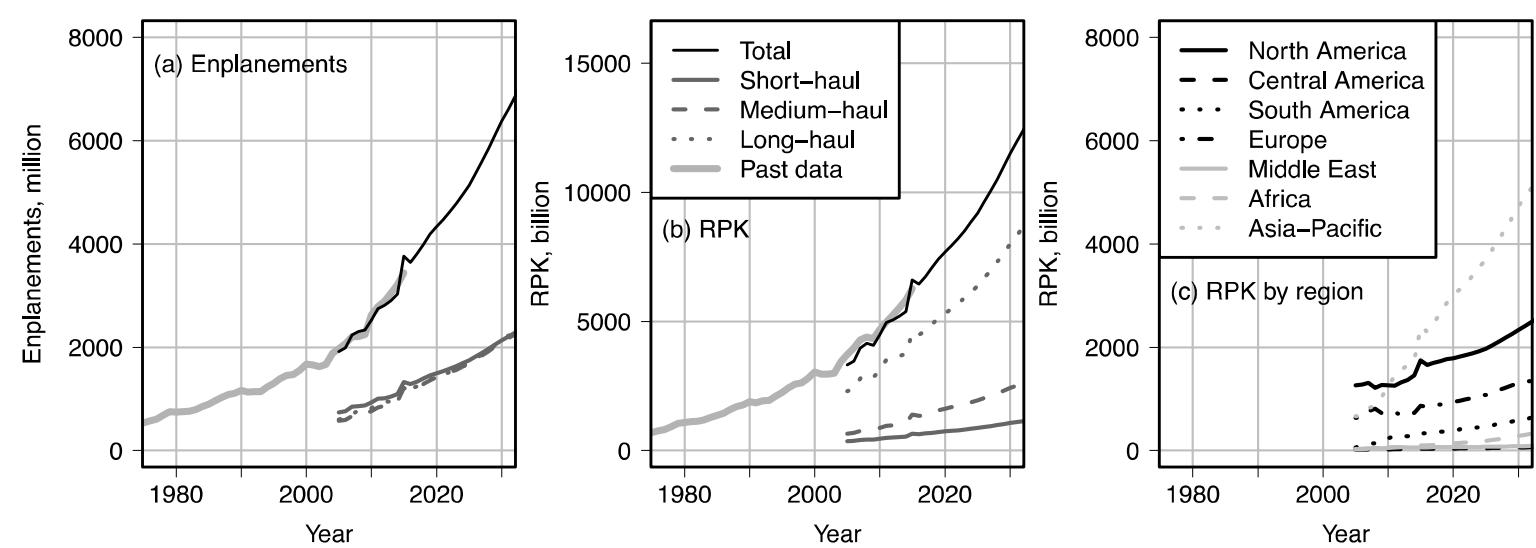

Figure 6. Enplanements and RPK from the 2005 base year hindcasting model.

Running AIM with 2005 base year data predicts 2015 total demand well. For example, projected global RPK is 6,613 billion compared to an actual value of 6,267 billion, a difference of just over five percent. The model also projects the larger growth in long-haul RPK compared to short-haul. Average regional growth rates are broadly as expected (Figure 7 (c)); for example, ICAO (2016) give year 2015 RPK totals for the North American and Asia-Pacific regions as 1,629 billion and 2,018 billion respectively; we project 1,744 billion and 2,401 billion, a difference of $7 \%$ and $18 \%$ respectively. The small peak in modelled demand in 2015 reflects the large variations in oil price over the 2014-2016 time period and their impact on modelled ticket prices. We do not model the impact of hedging on airline fuel costs or time lags between fuel price rises and ticket price rises, both of which will act to smooth out the impact of fluctuations in the oil price over time.

In Figure 7 we compare the actual and modelled flight networks for 2015. The upper lefthand panel shows the 2015 network modelled by the 2005 base year model, in comparison to the modelled network in 2005 (lower left-hand panel), the 2015 base year model in 2015 (upper right-hand panel) and actual network in 2015 (lower right-hand panel). Although 
overall total demand is at a similar level, the 2005 base year model tends to concentrate more demand on busy routes than the actual 2015 network, particularly in Asia and South America. This may be a consequence of the network model used; although we allow passengers to shift between different itineraries, we currently do not allow airlines to add new segments to the network. This means the model does not catch the opening up of new routes, instead routing these passengers via hubs on existing routes.
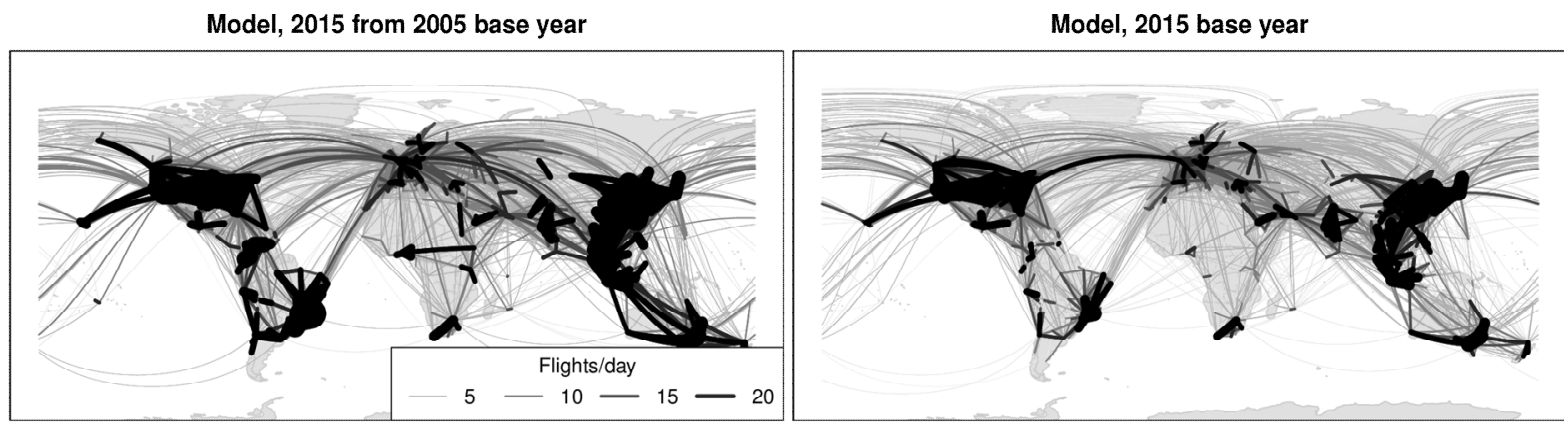

Model, 2005 base year Actual network, 2015 base year
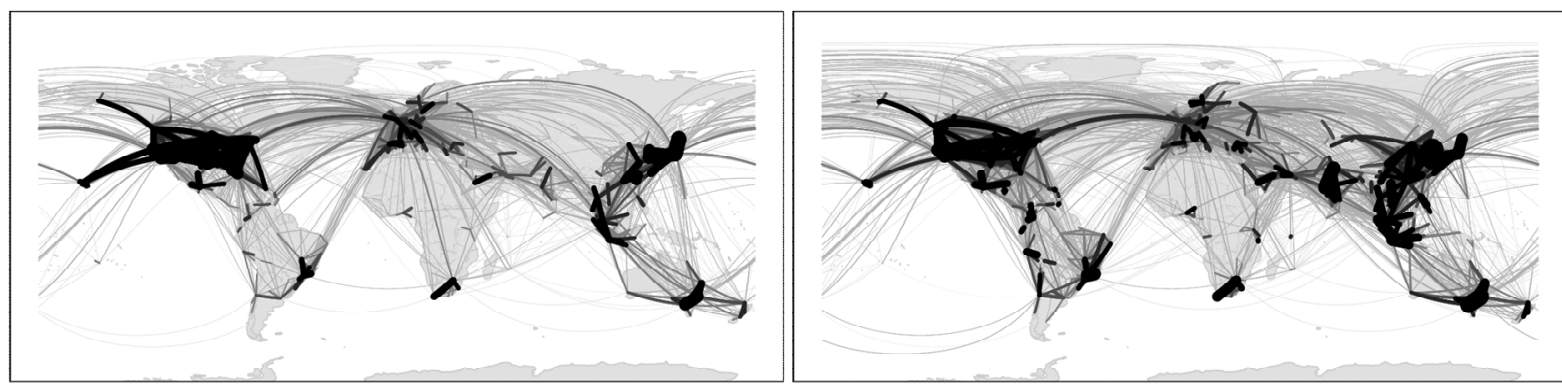

Figure 7. Modelled and actual flight networks.

\subsection{5 base year model}

We obtain 2015 base year data from a variety of sources; major data sources include Sabre (2016) for schedule and passenger demand-related data, BTS (2017) for airline cost data, FlightGlobal (2017) for fleet data, RDC (2017) for en-route and landing charges and FlightStats (2016) for data on passenger delays. Figure 7 shows the model base year flight network in comparison to actual values. A comparison of the year 2015 base year model airport demand to observations was also made in Figure 2. We project base year global 
scheduled passenger enplanements and RPK of 3,400 million and 6,200 billion respectively, within $2.5 \%$ and $1 \%$ of the actual values (ICAO, 2016).

To use the model to predict future demand we need scenarios which project key input variables into the future. A recent range of scenarios for future GDP and population is available from O'Neill et al. (2013). These scenarios, SSP1-SSP5 in Figure 8, were developed for the IPCC fifth assessment report and cover a wide range of internally consistent futures. For oil prices we use fossil fuel price projections from DECC (2015; panel (c) in Figure 8). We use the central oil price projection with the central SSP2 scenario. We pair the higher GDP growth scenarios, SSP1 and SSP5, with the DECC low oil price projection, to obtain scenarios in which we would expect more rapid growth in aviation demand. Similarly, we pair SSP3 and SSP4, which have lower GDP growth, with the high oil price projection, to make scenarios in which we would expect lower growth in aviation demand and emissions. 

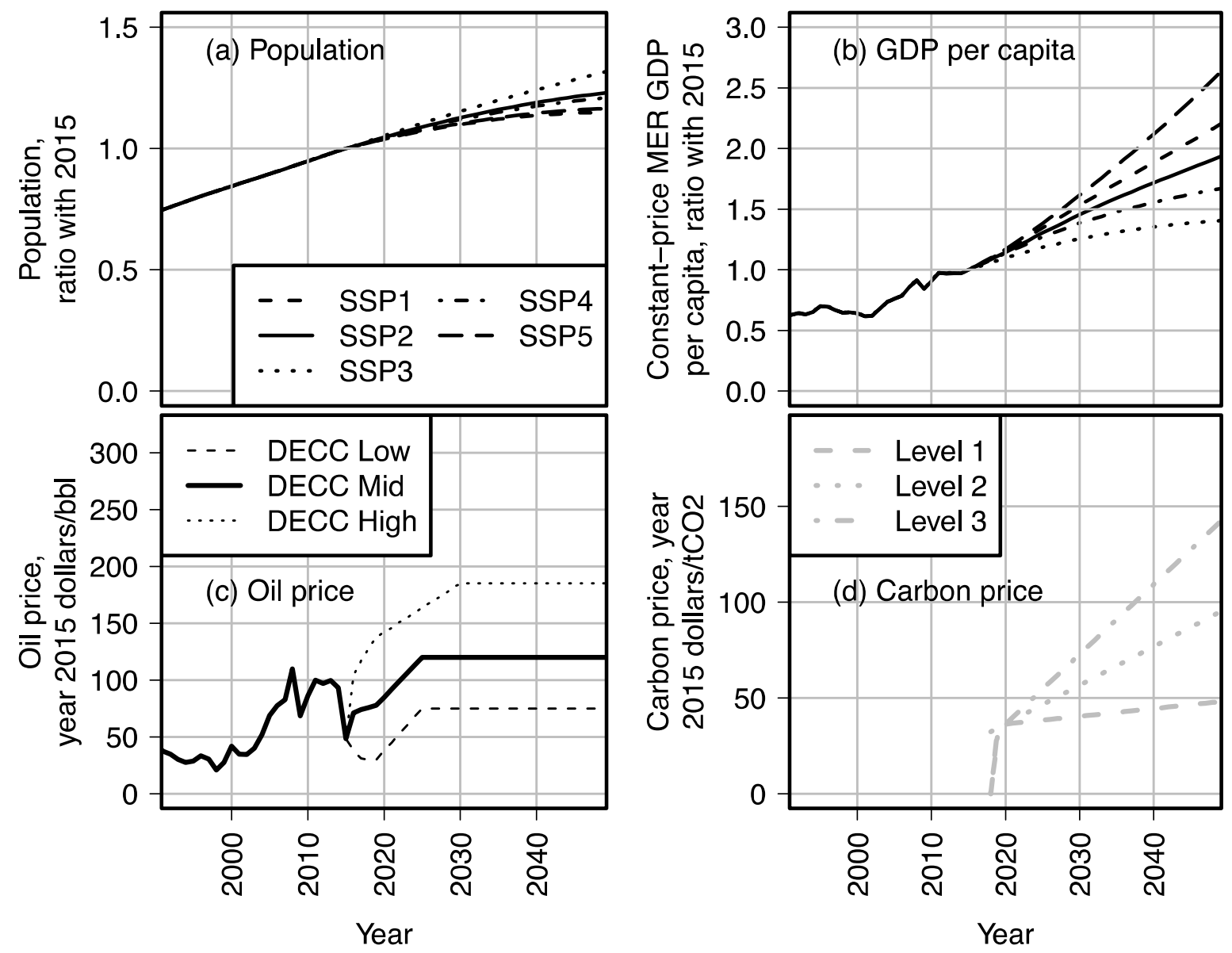

\section{Figure 8. Model input scenario data.}

The baseline input scenario data is one source of variability in the final model outcomes.

Another is the application of policy levers to the future system. The model design allows for policy levers to be applied in various areas, for example restrictions on technology availability, increased landing charges by aircraft type, or ticket taxation. For this paper we use carbon pricing as an example. Panel (d) in Figure 8 shows a range of hypothetical global carbon price scenarios. As we are interested in using these to assess the model's response to increasing the airline cost of carbon rather than modelling a specific policy, in our carbon price scenarios we apply them globally to all flights, without a threshold value or grandfathering. A third source of variability in the outcomes is uncertainty in the model input parameters. As discussed in Section 2.8, for uncertainty in the characteristics of future 
technology measures we use a lens approach ${ }^{\S \S}$. We construct a central lens using mid-range characteristics plus two additional lenses chosen to reflect futures in which it is particularly easy or difficult to reduce emissions using technology.

To assess the variability in model outcomes absent any radical societal, technological or operational change, we therefore carry out model runs on a grid over SSP scenario, technology lens and carbon price scenario. The global-level results are shown in Figure 9. The grey bands beneath each line show the range of variability due to technology lens. For clarity, we show only the baseline (zero carbon price) and Level 3 carbon price runs, over the full range of baseline scenarios.

Panels (a) and (b) of Figure 9 show enplanements and RPK in comparison to historical data from World Bank (2016). Panel (c) shows global system average passenger fare per RPK, in comparison to historical passenger revenue per RPK data from $\operatorname{ICAO}(2007,2016)$. Fare trends largely reflect the underlying trends in fuel cost and passenger numbers. Increasing passenger numbers allow airlines to take advantages of economies of scale, reducing ticket prices. Therefore average modelled fares initially fluctuate as fuel prices change, and then gradually decrease once the input oil price stabilises (panel (c) of Figure 8). Panel (d) shows the global fleet over all size classes compared to historical fleet data from FlightGlobal (2016). Panels (e) and (f) show fuel use and emissions, in comparison to past data from all aviation sources from IEA (2017). As we model only scheduled passenger traffic, we expect the model to produce lower base year fuel use and emissions than the observed values for all aviation. In particular, freight in 2015 accounted for around $24 \%$ of global aviation tonne-km

\footnotetext{
$\S \S$ A lens is a set of input parameters which reflect a particular scenario for future technology. For example, we use one lens for a future in which it is particularly hard to reduce aviation emissions through technology; this assumes the reduction in fuel use from new technologies is at the low end of available estimates, costs are at the high end of available estimates, and the date from which the technology is available is at the late end of available estimates. Further discussion, including the parameters and ranges used, is given in Dray et al. (2018).
} 
performed (ICAO 2016). We take account of hold freight in passenger aircraft when

modelling aircraft weight load factor, but do not account for dedicated freighter aircraft,

which carry around $40 \%$ of air freight (FTA 2008). Unscheduled passenger flights accounted for 5\% of global RPK in 2015 (ICAO 2016), and military aviation has been estimated to be around $10-13 \%$ of aviation fuel use (Wilkerson et al. 2010). Therefore we expect our base year totals to be approximately $30 \%$ below the IEA totals, as observed.
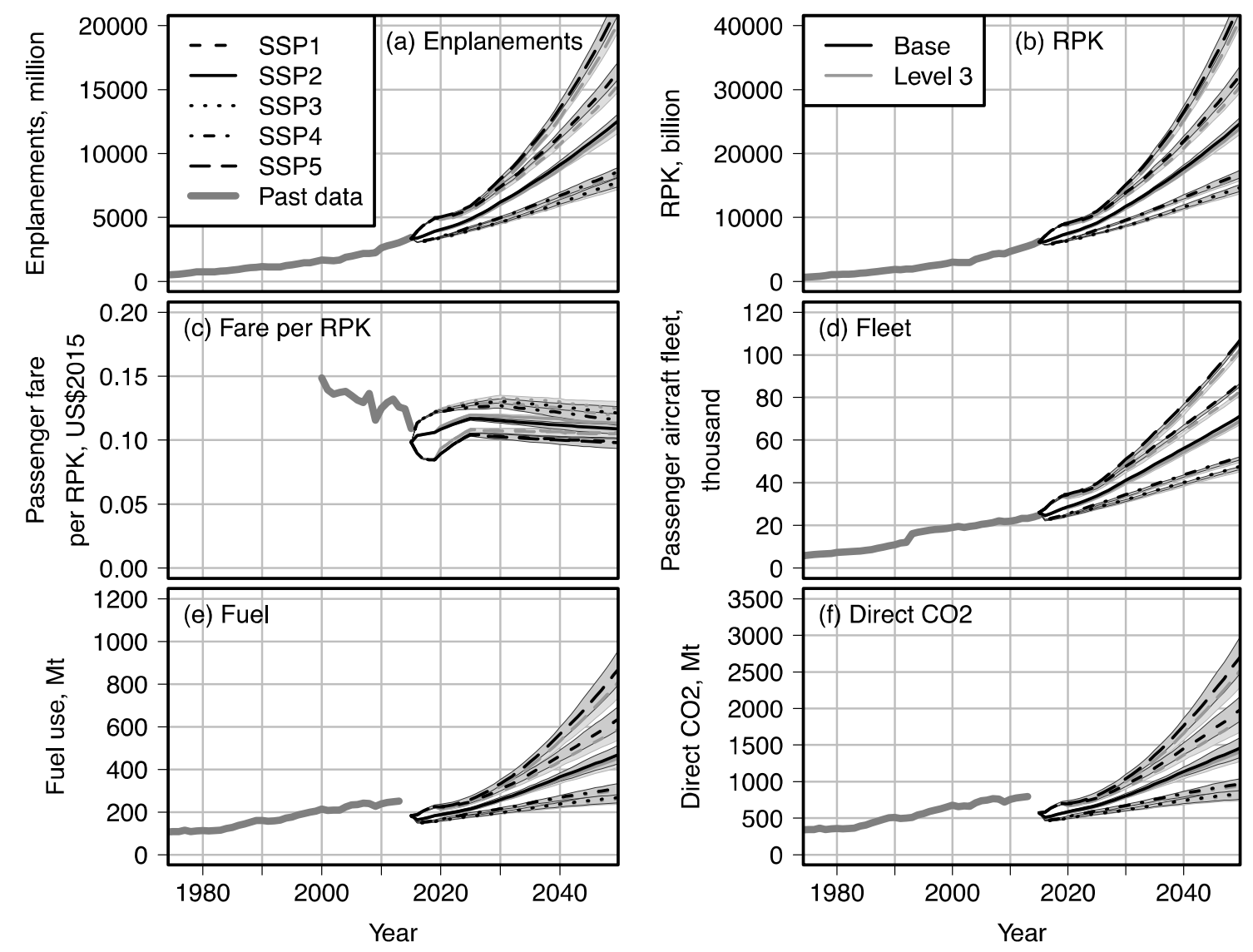

Figure 9. Enplanements, RPK, average system fare, fleet, fuel use and direct $\mathrm{CO}_{2}$ emissions for the grid of model runs over baseline scenario, carbon price and technology lens for the world aviation system.

Several outcomes are apparent from the projections of future trends. First, there is a large range of variability in aviation outcomes by 2050. Although demand grows in all scenarios, the projected year 2050 global RPK ranges between 13,800 billion and 46,000 billion, 2.2 and 7.4 times the year-2015 values respectively. Considering only central lens, zero carbon 
price scenarios, the highest-RPK scenario in 2050 has 3 times the RPK of the lowest-RPK one. If considering all scenarios, this ratio is 3.3 , i.e. the most important source of the variability in outcomes is the scenario used for future trends in socioeconomic variables.

The impact of uncertainty in future technology characteristics is somewhat smaller in these runs. For example, the SSP2 pessimistic and optimistic lenses differ by $7.1 \%$ in year 2050 RPK and $20 \%$ in year 2050 fuel consumption. This is partially an outcome of the relatively short time horizon: the technologies with the biggest impact on emissions per RPK are typically new aircraft models, which take a long time to percolate into the fleet. Technology characteristics which are uncertain include fuel use and cost; their impact on enplanements and RPK results from the impact these variables have on ticket prices and hence demand.

Carbon price also has a relatively limited impact at the levels modelled in this paper. Lines in light grey show scenarios in which the highest carbon price shown in Figure 8(d) is applied globally, reaching 150 dollars per tonne of $\mathrm{CO}_{2}$ by 2050. This results in reductions in fuel use and emissions of around 3-8\% across scenarios. This is a relatively high carbon price: for example, the highest carbon price in the EU emissions trading scheme to date occurred in 2008 and was equivalent to around 36 (year 2015) dollars per tonne of $\mathrm{CO}_{2}$ (European Climate Exchange, 2017). However, it has little effect on fares and demand compared to the baseline scenario. For example, for an Airbus A320 flight of 2,000 km with an 0.7 load factor, around $0.18 \mathrm{tCO}_{2}$ per passenger is emitted; therefore the cost to the airline per passenger for carbon from this flight is around 27 dollars. However, the ticket price elasticity for changes in fuel-related costs is typically close to 0.3 (Wang et al. 2017). This results in a fare per RPK increase of only around 0.01 dollars at base year fuel prices, as can be seen in Figure 9(c). 
To assess the model sensitivity to changes in income elasticity assumptions, we also run the demand model for the SSP1-5 base scenarios to 2050 with elasticities which are 0.2 lower for each region-pair and distance band. This is roughly the level of reduction to 2050 modelled in DfT (2017) to reflect market maturity, and represents a scenario in which markets mature quickly across all world regions. In this case, both RPK and enplanements in 2050 are reduced by between 10 (SSP3) and 19\% (SSP5) in 2050 from the case where income elasticities remain unchanged. This would lead to a similar level of variation in fuel use and $\mathrm{CO}_{2}$ outcomes to that from uncertainties in technology characteristics. However, both are much lower than the level of variation in outcomes due to socioeconomic scenario.

These scenarios can also be compared to other projections. Airbus (2016) project average demand growth over the 2015-2035 period of 4.5\% per year in RPK, resulting in 32,000 new passenger aircraft of 100 or more seats by 2035 over the $2015-2035$ period, around 20,000 of which are to serve new growth rather than replacing retiring aircraft. Boeing (2016) predict average global growth in RPK of $4.8 \%$ per year over the same time period, with fleet growth of around 23,000. We project average yearly demand growth of between $2.3 \%$ and $6.2 \%$ per year over this time period, with the central SSP2 scenario having a 4.4\% growth rate. Around 8,800 to 39,000 new aircraft of 100 or more seats would be needed to serve new growth over this time period, with the central SSP2 scenario requiring 22,500 new aircraft. Although the Airbus and Boeing projections are broadly central in these ranges, we typically project a slightly larger requirement for aircraft per RPK, most likely because we project a slightly smaller average aircraft size.

\section{CONCLUSIONS AND FUTURE MODEL DEVELOPMENT}

In this paper we presented the first version of the updated AIM model and demonstrated how it performs under various scenario conditions. This represents a first step towards the use of 
the model in assessing implications resulting from airport capacity decisions; the current model is also useful more generally in assessing environmental policy and is available as open-source code.

We find a wide range of plausible future outcomes, driven largely by the choice of external scenario for socioeconomic variables. The global demand for RPK in 2050 ranges between 2.2 and 7.4 times current values in the set of model runs shown in this paper, which uses the IPCC SSP1-5 scenarios (O’Neill et al. 2013). In the absence of any radical change in aircraft technology or operations, this would lead to year-2050 $\mathrm{CO}_{2}$ emissions of between 876 and 2,500 Mt, respectively 1.5 and 4.4 times year-2015 values. The highest- and lowest-growth scenarios both represent plausible futures, but the response required in each in terms of capacity and environmental policy may be very different. This applies particularly where policy measures take effect over a long timescale, e.g. when influencing aircraft fleet composition and technology uptake, and especially for many capacity and infrastructure decisions. Policymaking in such circumstances needs to take account of a range of possible futures and consider options that are either effective throughout those futures or adaptive to ongoing changes (Walker et al. 2002). For example, in the lowest-growth scenarios reaching a given aviation $\mathrm{CO}_{2}$ target may be more straightforward and may be achievable primarily via technological and operational change (for example, widespread use of biofuels, or radical new aircraft technology; Dray et al. (2018)). However, the lower growth also means that fleet turnover will be slower, limiting the rate at which new technologies can enter the fleet and thus potentially making policies based on promoting the adoption of new technology less successful than projected. In the highest growth scenario, meeting aviation-specific $\mathrm{CO}_{2}$ emissions goals will be extremely difficult even with successful and rapid technological change. Policy in this case may need to either address levels of demand growth and/or 
significant emissions mitigation in other sectors, for example via aviation carbon trading or offset-type schemes.

The model presented here is a work in progress and many areas have been flagged above to address in subsequent versions. To proceed towards the capacity-assessment model as discussed in the introduction, the new components developed here need to be integrated into a framework for airline network and frequency decision-making (e.g. Evans \& Schäfer, 2011); the demand, cost and itinerary choice models need additionally to assess airline choice for major airline alliances; and a more thorough assessment of airport capacity and stakeholder responses to airports nearing capacity needs to be undertaken. These efforts are all currently ongoing.

\section{REFERENCES}

AERO. Aviation Emissions and Evaluation of Reduction Options, Main Report. Directorate General for Civil Aviation: The Hague, 2002.

Airbus. Global Market Forecast 2016-2035. Airbus: Toulouse, 2016.

Aircraft Commerce, 2017. Maintenance and Engineering section. http://www.aircraftcommerce.com/articles/browsearticles.asp?cID=36461852\&path=true [Accessed May 2017]

Airports Commission, 2015. Airports Commission: Final Report.

https://www.gov.uk/government/uploads/system/uploads/attachment_data/file/440316/airport s-commission-final-report.pdf [Accessed April 2017]

Allaire D, Noel G, Willcox K and Cointin R. Uncertainty quantification of an Aviation Environmental Toolsuite. Reliability Engineering and System Safety, 2014; 126:14-24. 
Al Zayat, K., Dray, L., Schäfer A., 2017. A Comparative Analysis of Operating Cost between Future Jet-Engine Aircraft and Battery Electric Aircraft. 21 $1^{\text {st }}$ ATRS Conference, Antwerp, 58 July 2017.

Barrett, S. and Britter, R., 2009. Algorithms and analytical solutions for rapidly approximating long-term dispersion from line and area sources. Atmospheric Environment 43, 3249-3258.

Bhadra D. Choice of Aircraft Fleets in the US NAS: Findings from a Multinomial Logit Analysis, 3rd AIAA ATIO Conference, Denver, CO, 2003.

Boeing. “Current Market Outlook 2016-2035”. Boeing: Seattle, 2016.

Brons, M., Pels, E., Nijkamp, P., Rietvald, P., 2002. Price elasticities of demand for passenger air travel: a meta-analysis. Journal of Air Transport Management, 8(3), 165-175.

BTS, 2017. Form 41 airline costs database. https://www.transtats.bts.gov/

Coldren GM, Koppelman FS, Kasturirangan K and Mukherjee A. Modeling aggregate airtravel itinerary shares: logit model development at a major US airline. Journal of Air Transport Management, 2003: 9(6); 361-369.

DECC, 2015. Fossil fuel price projections: 2015. https://www.gov.uk/government/publications/fossil-fuel-price-projections-2015 [Accessed April 2017]

DfT, 2017. UK Aviation Forecasts. https://assets.publishing.service.gov.uk/government/uploads/system/uploads/attachment_data /file/674749/uk-aviation-forecasts-2017.pdf [Accessed November 2018]. 
Dray, L., 2013. An analysis of the impact of aircraft lifecycles on aviation emissions mitigation policies. Journal of Air Transport Management, 28, 62-69.

Dray, L., 2018. AIM2015: Documentation. http://www.atslab.org/wpcontent/uploads/2018/08/AIM-2015-Documentation-v9-30082018.pdf [Accessed November 2018].

Dray, L., Evans, A., Reynolds, T.G., Schäfer, A., Vera-Morales, M. and Bosbach, W. Airline fleet replacement funded by a carbon tax: an integrated assessment. Transport Policy, 2014; 34: $75-84$.

Dray, L. et al., 2017. AIM2015 Model Documentation. Air Transportation Systems Lab, UCL, London. $97^{\text {th }}$ TRB Annual Meeting, Washington, accepted.

Dray, L., Schäfer, A. and Al Zayat, K., 2018. The global potential for $\mathrm{CO}_{2}$ emissions reduction from jet engine passenger aircraft.

European Climate Exchange, 2017. Carbon prices on the European Climate Exchange. http://www.ecx.eu/

Eurostat, 2016. Population and household income data. http://ec.europa.eu/eurostat.

Evans, A. D. 2008. Rapid modelling of airport delay. $12^{\text {th }}$ Air Transport Research Society (ATRS) World Conference, Athens, Greece, July 6-10.

Evans A. D. and Schäfer A, 2011. The Impact of Airport Capacity Constraints on Future Growth in the United States Air Transportation System. Journal of Air Transportation Management, 17, 288-295.

FlightGlobal, 2016. Ascend Online Fleet Database. http://www.ascendworldwide.com/whatwe-do/ascend-data/aircraft-airline-data/ascend-online-fleets.html. [Accessed May 2017] 
FlightStats, 2016. Global Cancellation and Delay Database.

http://www.flightstats.com/go/Media/stats.do.

FTA, 2008. The role of air freight in the UK.

http://www.fta.co.uk/export/sites/fta/_galleries/downloads/air_freight/the-role-of-air-freightin-the-UK.pdf

Gallet, C., Doucouliagos, H., 2014. The income elasticity of air travel: a meta-analysis.

Annals of tourism research, 49, 141-155.

Graham, A., 2006. Have the major forces driving leisure airline traffic changed? Journal of Air Transport Management, 12, 14-20.

Hao, E., 2014. Ancillary Revenues in the Airline Industry: Impacts on Revenue Management and Distribution Systems. MIT Masters' thesis, June 2014.

https://dspace.mit.edu/bitstream/handle/1721.1/89854/890140266-MIT.pdf?sequence=2

IATA, 2007. Estimating air travel demand elasticities.

https://www.iata.org/whatwedo/Documents/economics/Intervistas_Elasticity_Study_2007.pd $\underline{\text { f }}$ [Accessed April 2017]

ICAO, 2009. Available capacity and average passenger mass. ICAO Working Paper STA/10WP/5. https://www.icao.int/Meetings/STA10/Documents/Sta10_Wp005_en.pdf [Sccessed May 2017]

ICAO, 2014. ICAO Annual Report, 2014: Appendix 1. https://www.icao.int/annual-report2014/Documents/Appendix_1_en.pdf [Accessed May 2017] 
ICAO, 2016a. Resolution A39-3. Consolidated statement of continuing ICAO policies and practices related to environmental protection. http://www.icao.int/environmentalprotection/Documents/Resolution_A39_3.pdf [Accessed April 2017]

ICAO, 2016b. ICAO Annual Report, 2016. http://www.icao.int/about-icao/Pages/annualreports.aspx [Accessed May 2017].

ICAO, 2017. Reduction of noise at source. http://www.icao.int/environmentalprotection/Pages/Reduction-of-Noise-at-Source.aspx [Accessed April 2017]

IEA, 2016. Energy prices and taxes online data service. http://www.iea.org/statistics/monthlystatistics/monthlyoilprices/

IEA, 2017. World Energy Statistics, 2016. http://www.iea.org/statistics/.

Krammer, P., Dray, L. and Köhler, M., 2013. Climate-neutrality versus carbon-neutrality for aviation biofuel policy. Transportation Research Part D, 23, 64-72.

Lissys, 2017. The PIANO X Aircraft Performance Model. www.piano.aero.

Madas, M. and Zografos, K., 2008. Airport capacity vs. demand: Mismatch or mismanagement? Transportation Research Part A, 42(1), 203-226.

Mayor, K., and Tol, R., 2007. The impact of the UK aviation tax on carbon dioxide emissions and visitor numbers. Transport Policy 14(6), 507-513.

O’Neill, B. C., Kriegler, E., Riahi, K., Ebi, K., Hallegatte, S., Carter T. R. et al. 2013. A new scenario framework for climate change research: The concept of shared socio-economic pathways. Climatic Change, 122(3), 387-400.

RDC, 2017. RDC Aviation airport and enroute charges databases. http://www.rdcaviation.com/. 
Reynolds T. G., Barrett, S., Dray, L., Evans, A., Köhler, M., Vera-Morales, M., Schäfer, A., Wadud, Z., Britter, R., Hallam, H. and Hunsley, R. 'Modeling Environmental and Economic Impacts of Aviation: Introducing the Aviation Integrated Modeling Project', Proceedings of the $7^{\text {th }}$ AIAA ATIO Conference, 2007.

Reynolds, T. G., 2009. Development of flight inefficiency metrics for environmental performance assessment of ATM. $8^{\text {th }}$ USA/Europe Air Traffic Management Research and Development Seminar, Napa, CA, June 29 - July 2.

Rich J, Bröcker J, Hansen CO, Korchenewych A, Nielsen OA, Vuk G., 2009. TRANSTOOLS version 2; Model and Data Improvements. TENConnect, Copenhagen, 2009.

Sabre, 2016. Market Intelligence passenger demand, routing and aircraft schedule databases. https://www.sabreairlinesolutions.com.

Summers, R., Heston, A. and Kravis, I., 2016. Penn World Tables.

http://cid.econ.ucdavis.edu/pwt.html [Accessed April 2017]

Schäfer, A., Evans, A., Reynolds T., Dray L., 2016. Costs of mitigating CO2 emissions from passenger aircraft., Nature Climate Change 6, 412-417.

Stalnaker, T., Usman, K. and Taylor, A., 2016. Airline Economic Analysis for the Raymond James Global Airline Book. Oliver Wyman, New York.

Sustainable Aviation, 2015. The SA Noise Roadmap. http://www.sustainableaviation.co.uk/wp-content/uploads/2015/09/SA-Noise-Road-MapReport.pdf [Accessed April 2017] 
Torija, A.J., Self, R. H. and Flindell, I. H., 2017. A model for the rapid assessment of the impact of aviation noise near airports. Journal of the Acoustical Society of America 141(2), 981-995.

US Census Bureau, 2016. American Community Survey data.

https://www.census.gov/programs-surveys/acs/

Waitz IA, Lukachko, S, Willcox K, Belobaba P, Garcia E, Hollingsworth P, Mavris D, Harback K, Morser F and Steinbach M., 2006. Architecture Study for the Aviation Environmental Portfolio Management Tool. PARTNER: Cambridge, 2006.

Walker, W., Rahman, S. and Cave, J., 2002. Adaptive policies, policy analysis and policymaking. European Journal of Operational Research, 128(2), 282-289.

Wang, B., O’Sullivan, A., Dray, L., Al Zayat, K. and Schäfer, A., 2017. Modelling the PassThrough of Airline Operating Costs on Average Fares in the Global Aviation Market. $21^{\text {st }}$ ATRS conference, Antwerp, 5-8 July 2017.

Wilkerson, J. T., Jacobson, M. Z., Malwitz, A., Balasubramanian, S., Wayson, R., Fleming, G., Naiman, A. D., Lele, S. K., 2010. Analysis of emission data from global commercial aviation: 2004 and 2006. Atmos. Chem. Phys., 10, 6391-6408.

World Bank, 2016. Global air transport data.

http://data.worldbank.org/indicator/IS.AIR.PSGR [Accessed May 2017] 